\title{
An effect of the ionospheric Alfvén resonator on multiband Pc1 pulsations
}

\author{
K. Prikner ${ }^{1}$, K. Mursula ${ }^{2}$, J. Kangas ${ }^{2}$, R. Kerttula ${ }^{2}$, and F. Z. Feygin ${ }^{3}$ \\ ${ }^{1}$ Geophysical Institute, Academy of Sciences of the Czech Republic, Bocni II, 14131 Praha 4, Sporilov, Czech Republic \\ ${ }^{2}$ Department of Physical Sciences, University of Oulu, P. O. Box 3000, FIN-90014 Oulu, Finland \\ ${ }^{3}$ United Institute of Physics of the Earth, Russian Academy of Sciences, Bolshaya Gruzinskaya 10, 123810 Moscow, Russia
}

Received: 9 September 2002 - Revised: 18 June 2003 - Accepted: 25 June 2003 - Published: 1 January 2004

\begin{abstract}
On 2 December 1999, the magnetometer stations in northern Finland registered structured Pc1 activity simultaneously in three distinct frequency bands. Using simultaneous EISCAT radar measurements of the high-latitude ionosphere, we have studied the ionospheric resonator properties during this multiband $\mathrm{Pc} 1$ event. The frequencies of the three structured Pc1 bands were found to closely correspond to the second, third and fourth harmonic of the calculated fundamental frequency of the ionospheric Alfvén resonator (IAR). In addition, those frequencies of the three pearl bands that were closest to the exact IAR harmonics were found to have the strongest intensities. The results demonstrate that the resonator can have an important role on ground-based Pc1 activity over a notably large frequency range, favoring transmission of waves with frequencies close to the resonator's eigenfrequencies. Since the frequencies of all three bands correspond to the maximum rather than the minimum of the transmission coefficient, the traditional bouncing wave packet model needs to be revised.
\end{abstract}

Key words. Ionosphere (auroral ionosphere; ionosphere magnetosphere interactions; wave propagation)

\section{Introduction}

Pc1 pulsations are magnetospheric electromagnetic ion cyclotron (EMIC) waves observed on the ground. At subauroral latitudes Pc1 events typically occur in the frequency range of $0.2-3.0 \mathrm{~Hz}$, showing only a single narrow frequency band in the dynamic spectrum. However, in addition to these single-band events, one sometimes observes two or even more bands occurring simultaneously. We call these phenomena multiband $\mathrm{Pc} 1$ events. There are two traditional mechanisms to explain the generation of multiband Pc1 activity: ionospheric waveguide ducting of $\mathrm{Pc} 1$ waves from multiple sources in the equatorial magnetosphere (Greifinger

Correspondence to: K. Mursula

(kalevi.mursula@oulu.fi) and Greifinger, 1968), and the spectral splitting by the magnetospheric heavy $\left(\mathrm{He}^{+}\right.$and $\left.\mathrm{O}^{+}\right)$ions (Young et al., 1981; Kozyra et al., 1984).

The effect of the ionosphere on Pc1 activity observed on the ground has received more observational evidence recently (Mursula et al., 2000; Prikner et al., 2000; Kerttula et al., 2001; Prikner et al., 2001). The Alfvén speed has strong gradients above the ionospheric $\mathrm{F}$ layer which can cause wave reflection and lead to the formation of a resonant cavity termed the ionospheric Alfvén resonator (IAR) by Polyakov and Rapoport (1981). Since the scale size of the resonator is of the order of the Pc1 wavelength, it is able to trap Pc1 waves incident from above the ionosphere and affect their spectral properties and even their appearance on the ground. For example, it has been found (Mursula et al., 2000) that the Pc1 frequency on the ground corresponds to the frequency of the first maximum (minimum) of the transmission (reflection) coefficient, i.e. to the fundamental frequency of the resonator (Lysak, 1991, 1993). This indicates that the IAR can act as a band-pass filter for Pc1 waves and determine, together with the magnetospheric wave source, the frequencies of the waves that can be observed on the ground.

Earlier studies of the IAR effects on ground-based Pc1 pulsations have mainly concentrated on single-band events. In this paper we study the resonator properties during a multiband Pc1 event by using EISCAT radar measurements of the ionosphere above the station detecting Pc1 signals. The obtained results demonstrate that the IAR can affect groundbased Pc1 activity over a notably large frequency range.

\section{Observations}

\subsection{Pc1 dynamic spectrum}

Figure 1 shows the dynamic spectrum of the D-component of multiband Pc1 pulsations registered at the Kilpisjärvi (KIL; geographic coordinates $69.0^{\circ}$ latitude, $20.9^{\circ}$ longitude, $65.9^{\circ}$ CGM latitude, $105.3^{\circ} \mathrm{CGM}$ longitude, $\mathrm{L}=6.0$ ) and Ivalo 

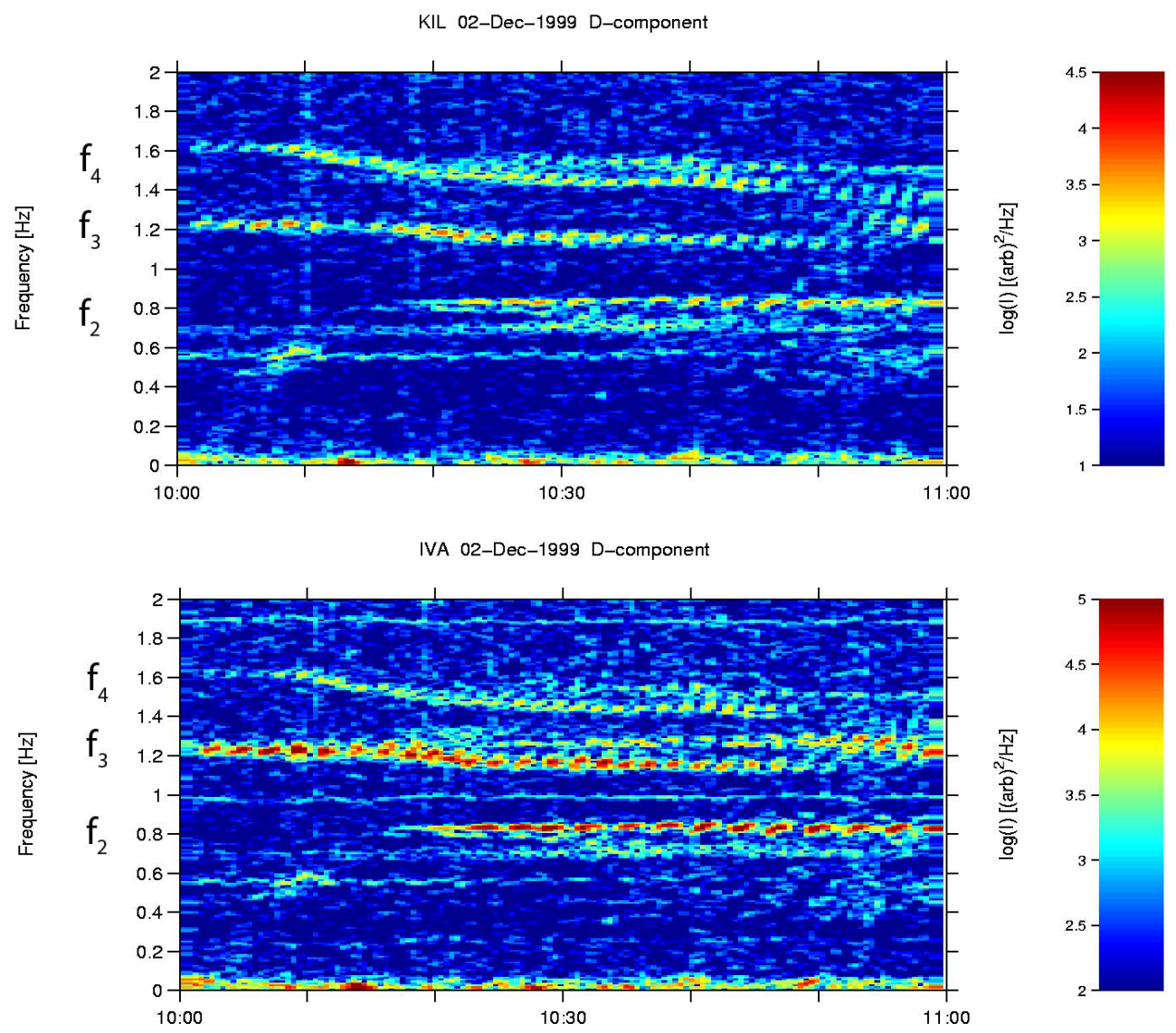

Fig. 1. The dynamic spectra (D-components) of a multiband Pc1 event registered at the Kilpisjärvi (KIL) and Ivalo (IVA) stations on 2 December 1999 between 10:00-11:00 UT.

(IVA, geographic coordinates $68.7^{\circ}$ latitude, $27.3^{\circ}$ longitude, 65.0 $0^{\circ}$ CGM latitude, $109.8^{\circ} \mathrm{CGM}$ longitude, $\mathrm{L}=5.6$ ) stations in northern Finland on 2 December 1999, from 10:00 to 11:00 UT. (There LT is about $2 \mathrm{~h}$ ahead of UT.) The magnetometer data (sampling rate $20 \mathrm{~Hz}$ ) have been analyzed using an FFT width (and spectral window size) of 2048 points, and a time step of 512 points.

At about 10:20-10:45 UT, both stations register three simultaneous and fairly stable frequency bands located at $f_{2} \sim 0.68-0.85 \mathrm{~Hz}, f_{3} \sim 1.12-1.31 \mathrm{~Hz}$, and at $f_{4} \sim 1.44-$ $1.57 \mathrm{~Hz}$. (Band numbering will be discussed in Sect. 2.3.) One can also see that there is a fourth narrow and much weaker band at $f \sim 0.53-0.59 \mathrm{~Hz}$ which is more pronounced at KIL. All the $f_{2}-f_{4}$ bands show systematic variation in intensity typical for the so-called structured or "pearl" pulsations. Moreover, the frequency range of about $0.2-2.0 \mathrm{~Hz}$ is typical for Pc1 pearls. At both stations, the intensity within the three pearl bands varies with frequency, so that the upper part of the $f_{2}$ band is more intense than the lower part, whereas the lower part dominates in the $f_{3}$ and $f_{4}$ bands. (Note that the upper $\sim 1.3 \mathrm{~Hz}$ part of the $f_{3}$ band is hardly visible at KIL.) The $f_{3}$ and $f_{4}$ bands do not last much longer than displayed in Fig. 1, whereas band $f_{2}$, starting at about 10:00 UT, lasted up to about 11:30 UT.
2.2 EISCAT measurements and the numerical method of the IAR simulation

Simultaneously with the multiband Pc1 activity, the EISCAT radar was monitoring the high-latitude ionosphere at Troms $\varnothing$. Since the radar operated in the CP1 mode, where the radar beam was directed along the background magnetic field, the measurements correspond quite well to the ionospheric conditions above KIL which is situated nearly at the same latitude but $\sim 2^{\circ}$ eastward of Troms $\varnothing$. Figure 2 depicts the altitude profiles of electron density from EISCAT observations (a), the modelled electron and ion collision frequencies (b), the local effective ion mass (c), and Alfvén velocity (d), up to $2000 \mathrm{~km}$ at 10:30 UT. One can see that all these profiles are very smooth, indicating very stable local ionospheric conditions at that time. The corresponding profiles (not shown) obtained at a slightly earlier $(\sim 10: 00$ UT), as well as at a later time $(\sim 12: 00$ UT) indicate that quiet conditions persisted during several hours. Quiet conditions are expected, since the Sodankylä $K$ index was 2, 0, 0, and 0 during the first four 3-hour intervals on that day.

Note that the EISCAT measurements extended only up to $600 \mathrm{~km}$ and that the profiles have been extrapolated from this altitude upward. Due to practical reasons concerning 

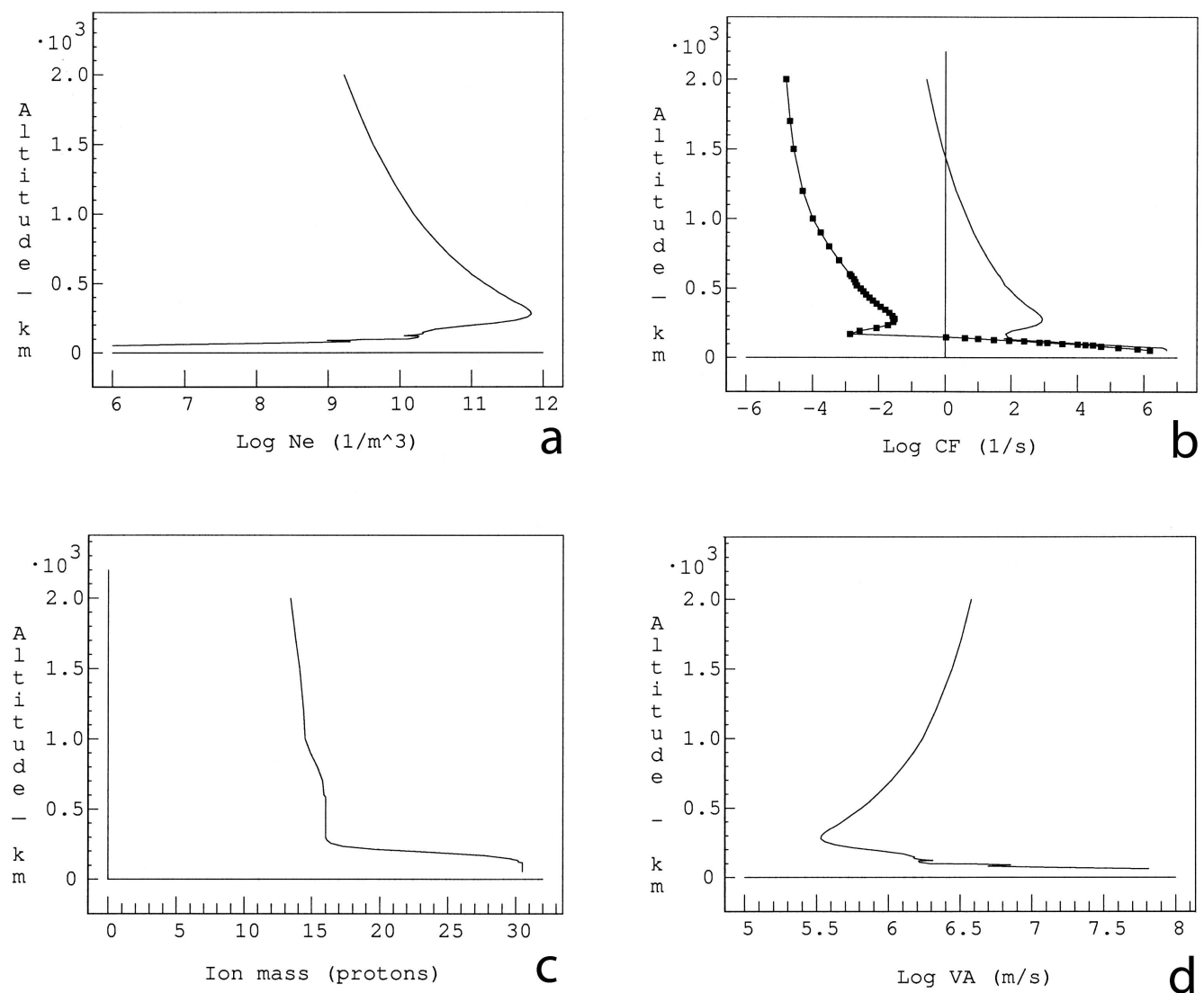

Fig. 2. The altitude profiles of electron density (a), electron (solid line) and ion (solid line with points) collision frequencies (b), local effective ion mass in units of proton mass (c), and Alfvén velocity (d) based on EISCAT measurements at Troms $\varnothing$ on 2 December at 10:30 UT. Note that extrapolation has been used at altitudes above $600 \mathrm{~km}$.

numerical simulation method, the ionospheric transmission layer has been constrained to a region where heavy ions (mainly $\mathrm{O}^{+}$) play a significant role, i.e. up to the altitude of about $2000 \mathrm{~km}$. The $\mathrm{O}^{+}$ion density was assumed to decrease exponentially with height. At higher altitudes the light ions $\left(\mathrm{H}^{+}\right.$and partially $\left.\mathrm{He}^{+}\right)$dominate, contributing mainly to wave attenuation, but not significantly to the resonator frequency characteristics. The decrease in $N_{e}$ is slower than the exponential due to the increasing content of the $\mathrm{H}^{+}$ions at higher altitudes. This can also be seen in Fig. $2 \mathrm{c}$ as a gradual decrease in the effective ion mass at altitudes above $700 \mathrm{~km}$.

The effect of the ionosphere on ion cyclotron waves was modelled using the $4 \times 4$-matrix procedure of Prikner and Vagner $(1983,1991)$. The simulation uses the following input data:

a) Characteristics of the plasma medium, including realistic height profiles of the electron density, effective ion mass and particle collision frequencies. The ionosphere is presented as a stack of thin $(10 \mathrm{~km})$ and homogeneous planar layers from $50 \mathrm{~km}$ up to $2000 \mathrm{~km}$ in an external dipole magnetic field with $M_{E}=8.17 \times 10^{22} \mathrm{~A} \mathrm{~m}^{2}$. Below $50 \mathrm{~km}$ the atmosphere is taken to be neutral and the conductivity of the Earth's surface is $10^{-2} \mathrm{~S} / \mathrm{m}$. b) Wave propagation characteristics, including the polarization of the incident homogeneous plane wave (in general Alfvénic $\mathrm{L}_{\| \text {- }}$ or isotropic R-mode), its frequency, and the orientation of the wave vector $\boldsymbol{k}$ with respect to $\mathbf{B}_{\mathbf{E}}(z)$ in the magnetic meridian plane. The inclination $\alpha_{E}$ of $\mathbf{B}_{\mathbf{E}}(z)$ is assumed constant with altitude above the ground and is negative in the Northern Hemisphere. We have assumed here a parallel incidence $\left(\mathbf{k}|| \mathbf{B}_{\mathbf{E}}\right)$ of a left-handed field-aligned Alfvénic $\left(\mathrm{L}_{\|}\right.$-mode) wave. Thus the incidence angle of $\mathbf{k}$ with respect to the horizontal plane $\beta_{\|}=-\alpha_{E}=77^{\circ}$ in the Kilpisjärvi region was used.

As an output from computations we obtain the altitude profiles of the complex amplitudes of the $E$ - and $B$-wave fields. Using this data we can determine the normalized real horizontal and vertical components of the wave fields at any frequency and altitude. Normalization is made by dividing the horizontal real wave amplitude by the corresponding amplitude of the incident wave. Thus, the reflection coefficient $\mathrm{RC}(f)$ is determined as the ratio of the reflected field magnitude on the upper boundary of the ionosphere to the magnitude of the incident wave, and the transmission coefficient $\mathrm{TC}(f)$ is the ratio between the wave transmitted to the ground and the magnitude of the incident wave. 

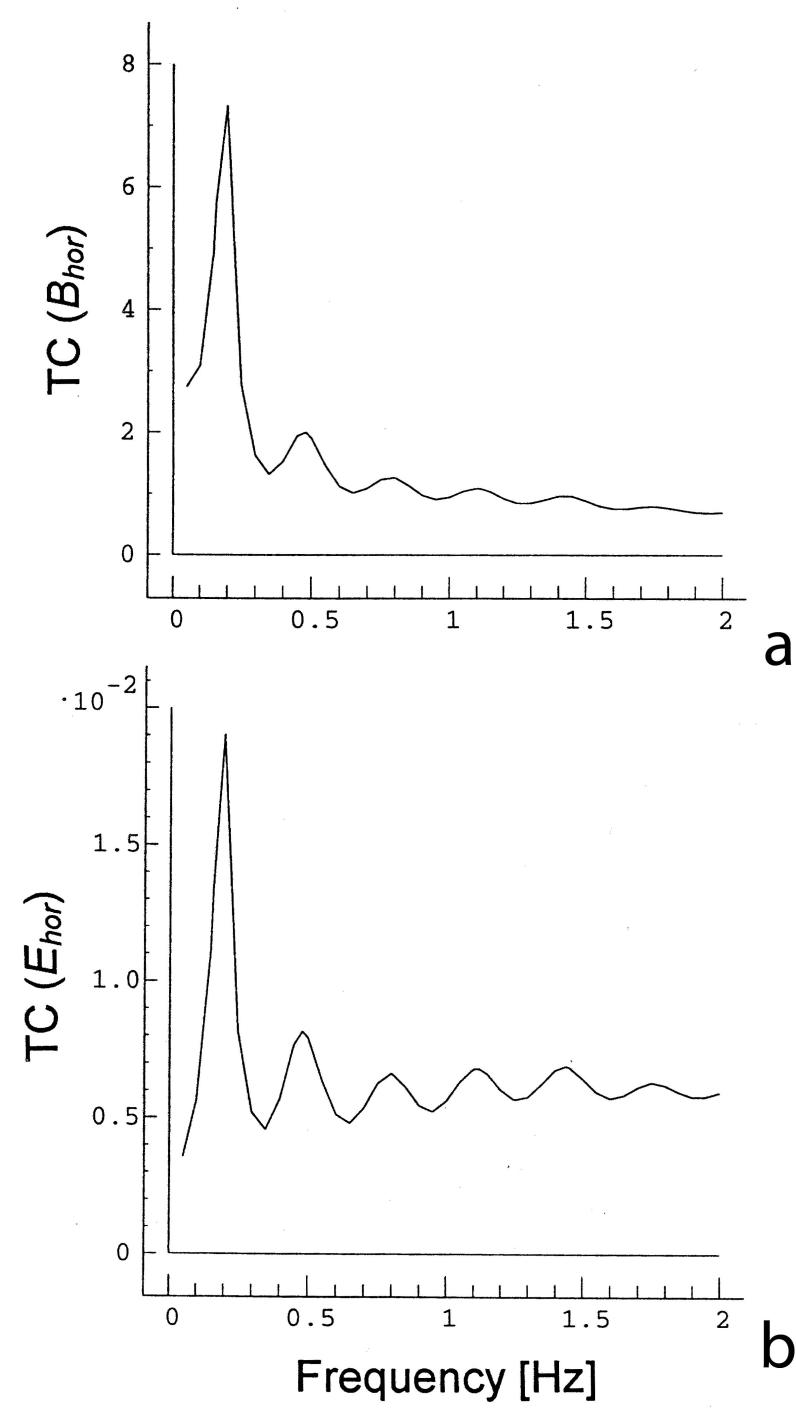

Fig. 3. The transmission coefficient of the left-handed field-aligned Alfvénic $\left(\mathrm{L}_{||}\right)$wave horizontal magnetic (a) and electric (b) field at 10:30 UT. The model ionosphere extends up to $2000 \mathrm{~km}$.

\subsection{Model results}

Figure 3 presents the frequency spectrum of the transmission coefficient of the horizontal component of the wave magnetic (a) and electric (b) field at 10:30 UT at Ivalo. As depicted in Fig. 3, altogether six maxima exist below $2.0 \mathrm{~Hz}$. The first and highest maximum at about $f_{0}=0.20 \mathrm{~Hz}$ corresponds to the fundamental frequency of the resonator and the five smaller maxima, located at $f_{1}=0.48 \mathrm{~Hz}, f_{2}=0.80 \mathrm{~Hz}$, $f_{3}=1.12 \mathrm{~Hz}, f_{4}=1.44 \mathrm{~Hz}$ and $f_{5}=1.75 \mathrm{~Hz}$ are correspondingly the first five harmonics. The TC maxima correspond to frequency windows for EMIC waves to propagate through the ionosphere to the ground. Note that the positions and widths of these maxima are mostly determined by the electron density profile. It is also important to note that reasonable variations in the extrapolated $N_{e}$-profile do not practically affect the positions of TC maxima.
Figure 4 depicts the calculated frequencies $f_{1}-f_{4}$ of the resonator's transmission maxima and the observed frequencies of the Pc1 bands at KIL between 10:00-11:00 UT at the EISCAT data sampling interval of $\Delta T=5 \mathrm{~min}$. The frequencies of all the three pearl bands $f_{2}-f_{4}$ correspond quite well to the respective harmonic frequencies of the resonator, in particular during the latter half of the interval studied. (The numbering of the Pc1 bands presented above is based on this correspondence.) However, this matching is slightly weaker in the case of the unstructured Pc1 band at $f \sim 0.53-0.59 \mathrm{~Hz}$. This may at least partly explain why the signal is so weak on the ground.

The normalized altitude profiles of the modeled wave magnetic (electric) horizontal and vertical components at frequencies $f_{0}-f_{4}$ are shown in Figs. $5 \mathrm{a}$ and $5 \mathrm{~b}(5 \mathrm{c}$ and $5 \mathrm{~d}$ ), respectively. As above, we have assumed a field-aligned incident $\mathrm{L}_{\|}$mode wave at 10:30 UT. The profiles of all these standing wave modes are highly non-monotonic in the vertical direction. The amplitudes of antinodes of $B_{\text {hor }}$ increase with decreasing altitude down to about $300 \mathrm{~km}$, which is opposite to $B_{\text {vert }}$ and both $\mathbf{E}$-field components. $B_{\text {hor maxima }}$ (i.e. antinodes) correspond to minima (nodes) in $B_{\text {vert }}$ and vice versa. The nodes (antinodes) in $B_{\text {vert }}$ coincide with the nodes (antinodes) in the both $\mathbf{E}$-field components. Thus, $B_{\text {hor }}$ is the largest component in the $\mathrm{F}$ region. This is also true on the ground, where only $B_{\text {hor }}$ has a perceptible value. We have also made calculations of the altitude profiles of the total Poynting vector for all harmonics using the method presented by Vagner (1982) and by Prikner and Vagner (1983, 1991). These calculations (not shown here) show that the normalized vertical component of the Poynting vector is practically constant in the whole ionosphere and always directed downwards.

\section{Discussion}

\subsection{Resonator properties}

Geomagnetic conditions were very quiet during the morning hours on 2 December 1999. At that time the EISCAT radar measured high electron densities around the $\mathrm{F}$ region maximum and a very smooth decrease in density at greater heights. These ionospheric conditions led to a formation of an ionospheric resonator with a fundamental frequency peak of about $0.20 \mathrm{~Hz}$. This is significantly smaller than the fundamental frequency of about $0.5 \mathrm{~Hz}$ found in our earlier study when a substorm process strongly decreased the resonator dimensions (Mursula et al., 2000; Prikner et al., 2000). The substorm effects on the ionosphere were discussed in terms of the formation of an ionospheric trough above the station observing an IPDP (Interval of Pulsations with Diminishing Period) wave event. The trough is formed during the substorm by enhanced electric currents which lead to a plasma outflow from the high altitude ionosphere and increase the $\mathrm{O}^{+}$density gradient. As a result of this outflow the IAR fundamental frequency increases, in accordance with the simul- 


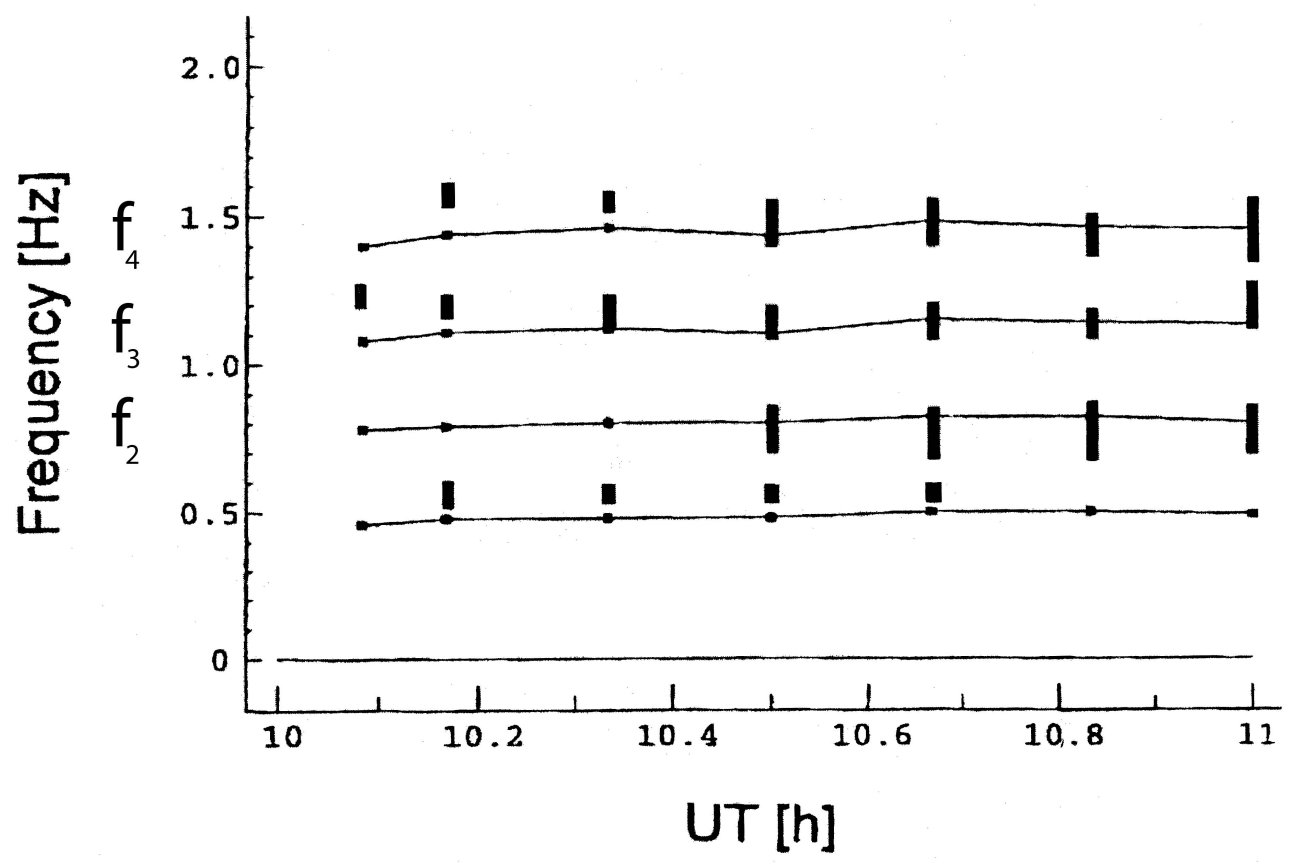

Fig. 4. Calculated harmonic frequencies of the resonator (horizontal lines) and the observed frequencies of the Pc1 bands (vertical lines) at KIL station on 2 December at 10:00-1100 UT. The calculations were carried out on the basis of the EISCAT data sampling intervals with $\Delta T=5 \mathrm{~min}$. The input parameters (incident $\mathrm{L}_{\|}$mode wave and $z_{\max }=2000 \mathrm{~km}$ ) are the same as in Fig. 3.

taneously observed increase in IPDP frequency. Moreover, the increase in fundamental frequency naturally leads to an increase in the harmonic frequencies. Thus, the harmonic frequencies during the substormrelated IPDP event studied by Mursula et al., 2000 were located above $1.5 \mathrm{~Hz}$, while four harmonics were found below $1.5 \mathrm{~Hz}$ in the present case. During quiet geomagnetic conditions, as studied here, the plasma density decreases more slowly with altitude. Accordingly, such conditions give lower resonator frequencies than substorm conditions and quiet geomagnetic conditions favor the formation of multiband Pc1 pulsations on the ground, as indicated by the present study.

\subsection{Multiband Pc1 pearls}

As seen in Fig. 1, a multiband pearl Pc1 event was observed at IVA and KIL during about $30 \mathrm{~min}$ around 10:30 UT. The pearl bands were located at $f_{2} \sim 0.68-0.85 \mathrm{~Hz}, f_{3} \sim 1.12-$ $1.31 \mathrm{~Hz}$ and at $f_{4}-1.44-1.57 \mathrm{~Hz}$. Pearls are the main type of Pc1 pulsations at low- and mid-latitudes (e.g. Benioff, 1960), showing often a close connection to the plasmapause (e.g. Fraser et al., 1989; Erlandson et al., 1992; Mursula et al., 2001). It is worthwhile to note here that the pearl structure is generated in the magnetosphere, and not in the ionosphere, for example due to the IAR operation. Conjugate studies where pearl events have been observed simultaneously on the ground and in the magnetosphere confirm the view that the pearl structure is indeed generated in the magnetosphere (Mursula et al., 2001). The traditional model assumes that pearls are due to a wave packet bounc- ing between the opposite hemispheres (Jacobs and Watanabe, 1964; Obayashi, 1965; Kenney and Knaflich, 1967). However, it has been found that the ionospheric reflection is very small (e.g. Erlandson et al., 1992; Mursula et al., 2000) while a rather strong amplification would be necessary in the source region in the standard bouncing model. According to an alternative model that has obtained more observational evidence recently, long-period ULF waves (Pc3-5 pulsations) modulate the equatorial plasma, leading to repetitive enhancements in the Pc1 intensity with a period of a modulating ULF wave (Rasinkangas et al., 1994; PlyasovaBakounina et al., 1996; Mursula et al., 1997; Rasinkangas and Mursula, 1998; Mursula et al., 2000; Mursula et al., 2001). In this model, the classical tenet of the bouncing wave packet model, the roughly alternate appearance of packets in conjugate hemispheres, may be explained by antisymmetric ULF wave modes. Note also that the ULF modulation operates more effectively in a region of large plasma density gradients. Therefore, both models naturally explain the well-known preferred occurrence of Pc1 pearls around the plasmapause (Mursula et al., 2001). However, it is clear that more studies, both by ground and satellite observations, are needed in order to re-examine these basic properties of pearl pulsations.

Let us next discuss the possible mechanisms producing the observed multiband pearls. A closer inspection of Fig. 1 shows that the pearl repetition period decreases with increasing band frequency. At about 10:20-10:45 UT, the average repetition periods for bands $f_{2}, f_{3}$ and $f_{4}$ are about $172 \mathrm{~s}$, $121 \mathrm{~s}$, and $98 \mathrm{~s}$, respectively. As a rough estimate, the av- 

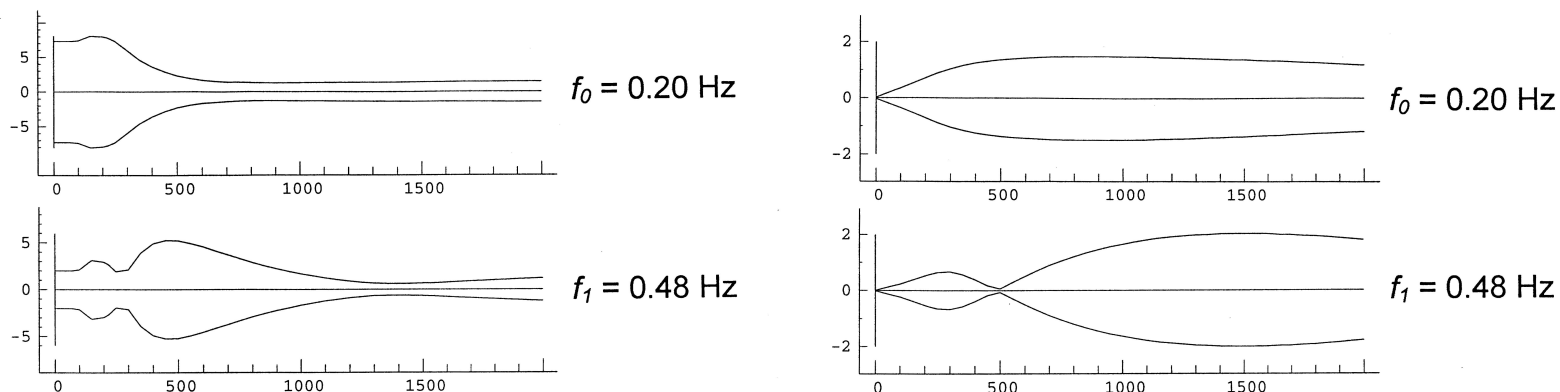

$f_{1}=0.48 \mathrm{~Hz}$
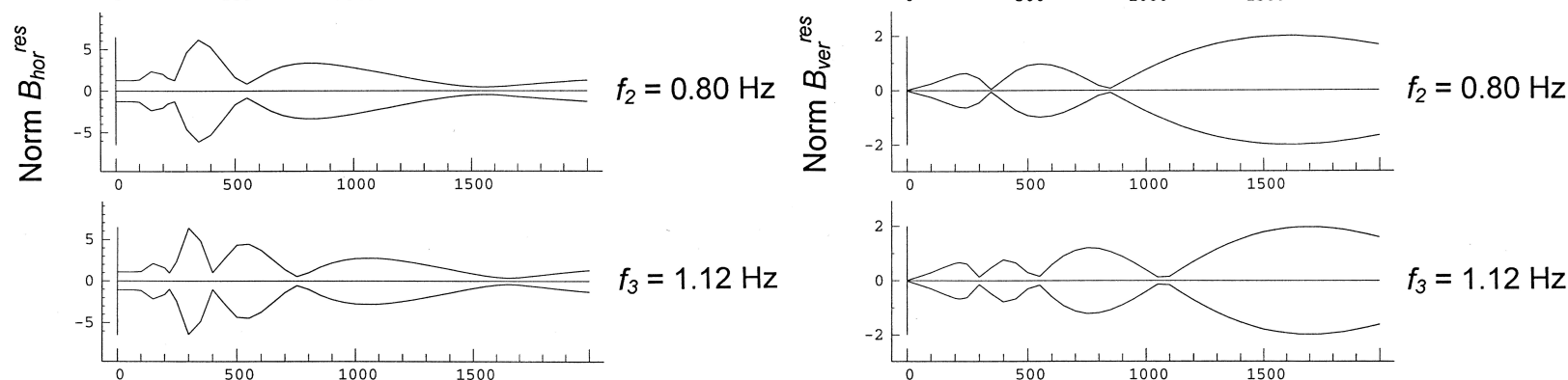

$f_{3}=1.12 \mathrm{~Hz}$
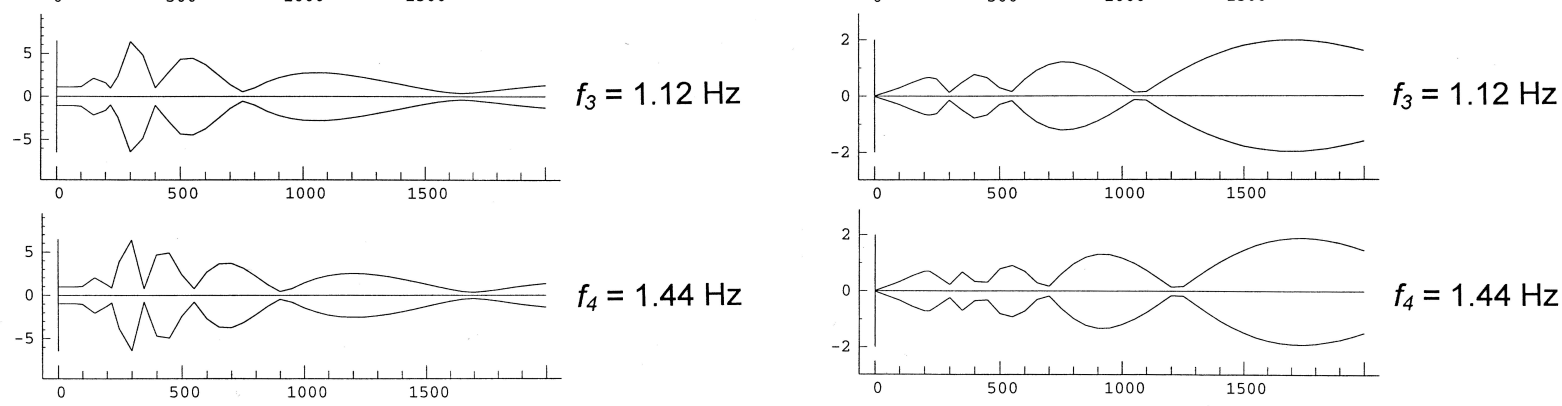

$f_{4}=1.44 \mathrm{~Hz}$

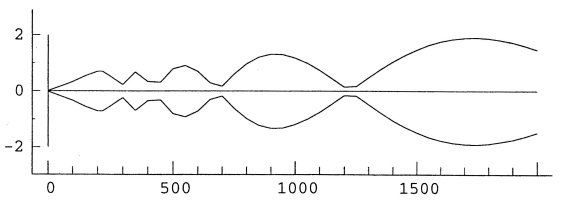

$f_{4}=1.44 \mathrm{~Hz}$

Altitude $[\mathrm{km}]$

a

Altitude [km]

b

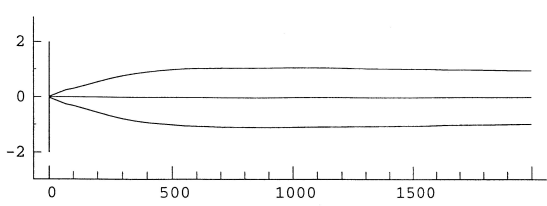

$f_{0}=0.20 \mathrm{~Hz}$

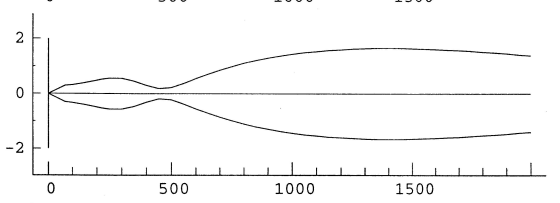

$f_{1}=0.48 \mathrm{~Hz}$

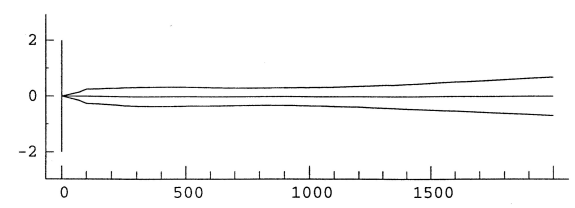

$f_{0}=0.20 \mathrm{~Hz}$

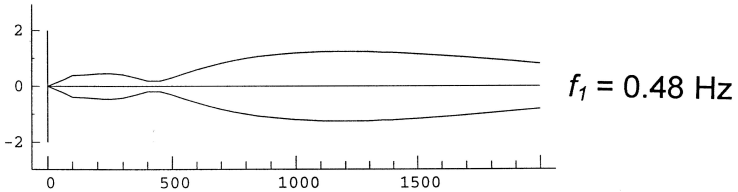

농
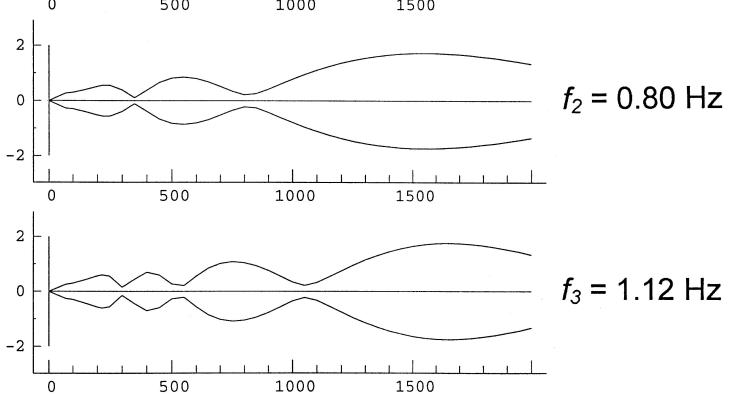

$f_{3}=1.12 \mathrm{~Hz}$
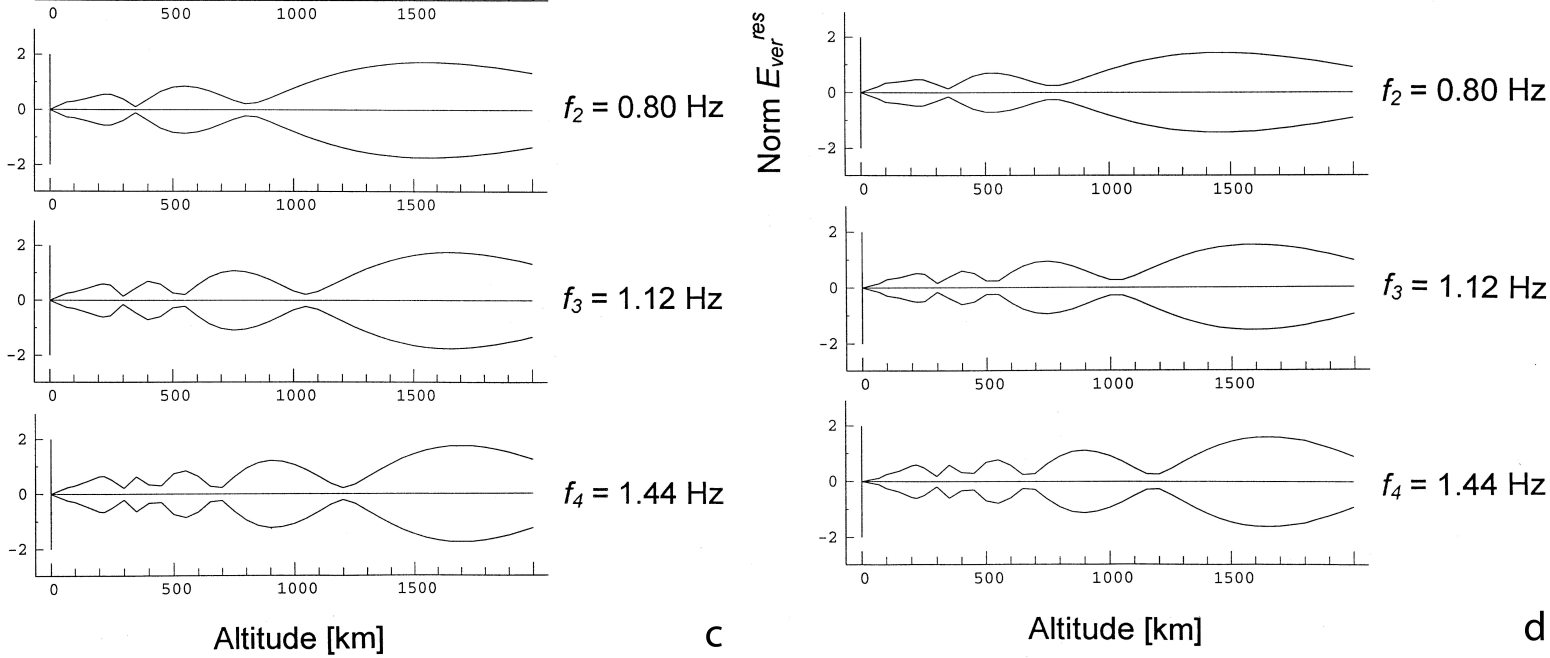

$f_{4}=1.44 \mathrm{~Hz}$

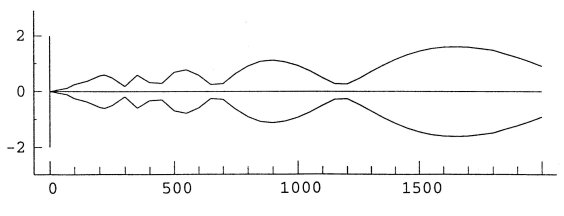

$f_{4}=1.44 \mathrm{~Hz}$

Altitude [km]

d

Fig. 5. The normalized altitude profiles of amplitudes of the magnetic field horizontal component $B_{\text {hor }}(\mathbf{a})$, the vertical component $B_{\mathrm{ver}}(\mathbf{b})$, the electric field horizontal component $E_{\text {hor }}(\mathbf{c})$, and vertical component $E_{\mathrm{ver}}(\mathbf{d})$ for frequencies $f_{0}$ and $f_{4}$. 
erage pearl dispersion around 10:30 UT for bands $f_{2}, f_{3}$ and $f_{4}$ is about $2300 \mathrm{~s} / \mathrm{Hz}, 1000 \mathrm{~s} / \mathrm{Hz}$ and $800 \mathrm{~s} / \mathrm{Hz}$, respectively (zero meaning no dispersion). In the bouncing wave packet model, the decreasing repetition period with increasing frequency can be explained by a shorter path length at lower L shells, where a higher magnetic field intensity yields a higher ion gyrofrequency and, correspondingly, a higher Pc1 wave frequency. In the ULF modulation model, this is explained by the shorter ULF period at inner L shells. The increasing pearl slopes (smaller dispersion) with increasing frequency indicate, in both models, that the pearl dispersion has less time to evolve on shorter field lines of the inner $\mathrm{L}$ shells. Accordingly, these two observations suggest that the three pearl bands are due to an ionospheric ducting of Pc1 waves from multiple sources, with the $f_{2}\left(f_{4}\right)$ band being generated in the outermost (innermost) $\mathrm{L}$ shell. The formula $\mathrm{L}_{\mathrm{p}}=5.6-0.46 \mathrm{~K}_{\mathrm{pmax}}$ (where $\mathrm{K}_{\mathrm{pmax}}$ is the maximum $\mathrm{K}_{\mathrm{p}}$ index in the preceding $24 \mathrm{~h}$ ) by Carpenter and Anderson (1992) gives an approximate plasmapause location $\mathrm{L}_{\mathrm{p}} \sim 4.7$ in the present case. This suggests that the source producing the pearl bands is situated at equatorial latitudes lower than KIL $(\mathrm{L}=6.0)$ and IVA $(\mathrm{L}=5.6)$.

On the other hand, multiband Pc1 activity can also be produced by magnetospheric heavy ions (mainly $\mathrm{He}^{+}$and $\mathrm{O}^{+}$). Dynamic spectra of Pc1 waves often show a gap in spectral power just above each heavy ion gyrofrequency (Mauk et al., 1981; Young et al., 1981; Kozyra et al., 1984). Theoretically, the wave growth is divided into separate branches divided by heavy ion gyrofrequencies. Assuming that the source containing heavy ions is located around $\mathrm{L}=4.5-5.0$, the approximate values of the equatorial $\mathrm{H}^{+}, \mathrm{He}^{+}$and $\mathrm{O}^{+}$gyrofrequencies in this $\mathrm{L}$ range vary for $\mathrm{H}^{+}$from $5.4 \mathrm{~Hz}$ to $3.9 \mathrm{~Hz}$, for $\mathrm{He}^{+}$from $1.3 \mathrm{~Hz}$ to $1.0 \mathrm{~Hz}$, and for $\mathrm{O}^{+}$from $0.3 \mathrm{~Hz}$ to $0.2 \mathrm{~Hz}$. Since the frequencies of all three pearl bands are much higher than the calculated $\mathrm{O}^{+}$gyrofrequency in this $\mathrm{L}$ shell range, $\mathrm{O}^{+}$ions were not able to produce any of these bands. (If the lowest band $f_{2}$ were produced by $\mathrm{O}^{+}$, the source should be at $\mathrm{L}<3.5$, which is unrealistically far inside from the estimated plasmapause.) Assuming that the source region is located around $\mathrm{L} \sim 5$, the $f_{2}$ band could then be produced by $\mathrm{He}^{+}$ions and the $f_{3}$ and $f_{4}$ bands by $\mathrm{H}^{+}$ ions. On the other hand, if the source region is around $\mathrm{L}$ $\sim 4.5$, the $f_{2}$ and $f_{3}$ bands could be produced by $\mathrm{He}^{+}$and $f_{4}$ by $\mathrm{H}^{+}$ions. This implies that in this scenario both $\mathrm{He}^{+}$ and $\mathrm{H}^{+}$ions would have been involved in the generation of the three bands. However, since the pearl repetition period and dispersion systematically correlate with band frequency, which cannot easily be explained in terms of heavy ions, we conclude that the multiband structure is probably due to the ionospheric ducting of waves from a radially wide multifrequency source in the equatorial magnetosphere. In order to fully solve the origin of this multiband event, satellite measurements of Pc1 waves would be needed from the equatorial magnetosphere (see related observations for another multiband Pc1 event in Mursula et al., 2001).
3.3 Correspondence of resonator harmonics and pearl Pc1 frequencies

Assuming a dipole field and using the observed wave frequencies we can calculate the L shell of band $f_{2}$ to be some $20 \%$ larger than that of band $f_{4}$. However, due to the convergence of field lines this implies an ionospheric distance of about $300 \mathrm{~km}$ between the footpoints of these waves. Taking into account the extremely quiet conditions, we can therefore neglect the latitudinal change of the ionosphere and use the same model ionosphere for all three wave bands. Moreover, the small difference in the wave inclination angle for calculations can be neglected (it does not affect substantially the transmission coefficient spectra).

As depicted in Fig. 4, the frequencies of the three Pc1 bands were found to coincide well with the resonator harmonics $f_{2}-f_{4}$ during most of the one-hour interval studied. This indicates that the resonator can act as a band-pass filter, determining the frequencies of Pc1 waves that can propagate to the ground. This result is in qualitative agreement with our earlier studies (Mursula et al., 2000; Prikner et al., 2001, 2002), where we found that the Pc1/IPDP frequency on the ground corresponds to the fundamental frequency of the resonator. However, there the resonator harmonics did not appear because of the effect of substorm activity on the resonator.

Further evidence for the possible resonator effect can be seen in Fig. 1. As already mentioned above, the Pc1 intensity during the one-hour interval is not the same over the band. This is true for both stations and all three bands. The high-frequency $(\sim 0.8 \mathrm{~Hz})$ part of the $f_{2}$ band is significantly stronger than the low-frequency $(\sim 0.7 \mathrm{~Hz})$ part. In contrast, in the case of the $f_{3}\left(f_{4}\right)$ band, the low-frequency $\sim 1.15 \mathrm{~Hz}$ $(\sim 1.45 \mathrm{~Hz})$ part of the band is more intense than the highfrequency $\sim 1.3 \mathrm{~Hz}(\sim 1.55 \mathrm{~Hz})$ part. This indicates that the resonator suppresses that part of the band whose frequency significantly differs from the respective harmonic frequency. Also, the weakness of the unstructured band at about $0.6 \mathrm{~Hz}$ may be due to the fact that its frequency is only partly coincident with the IAR $f_{1}$ frequency.

According to the bouncing wave packet hypothesis, pearl Pc1 waves can only grow at those frequencies where the ionospheric reflection coefficient (RC) has a maximum (e.g. Belyaev et al., 1984, 1987; Feygin et al., 1994). However, as shown above, the frequencies of all the three pearl bands correspond to a maximum of the modelled transmission coefficient and, therefore, to a minimum of the reflection coefficient. This gives further evidence to support our earlier view (Mursula et al., 2000), that the pearl generation cannot be explained in terms of the traditional bouncing wave packet model. Calculations (not shown here) indicate that even considerable changes in heavy ion concentration and slope of the exponential decrease of $N_{i}$ above $600 \mathrm{~km}$ do not significantly change the frequency spectra of TC and RC. In order to make a more detailed analysis, ionospheric (EISCAT) measurements up to about $2000 \mathrm{~km}$ during a Pc1 event would be helpful. 


\subsection{Normalized vertical profiles of wave characteristics}

As observed in Fig. 5, all the wave modes are highly nonmonotonic with altitude, because of the nearly exponential decrease of electron density above the F-region peak. At the fundamental frequency $f_{0} \approx 0.20 \mathrm{~Hz}$, the amplitude of $B_{\text {hor }}$ (Fig. 5a) exhibits a maximum at low altitudes and a minimum at high altitudes. This suggests that the resonator has a quarter-wave character at the fundamental frequency. Also, the four harmonics $f_{1}-f_{4}$ correspond to the odd multiples of the theoretical fundamental frequency of $0.16 \mathrm{~Hz}$. Such shifts in harmonic frequency are in accordance with earlier studies (see, e.g. Cummings et al., 1969; Takahashi and McPherron, 1982; Lysak, 1993, 1999), and a quarter-wave type nature of the resonator.

Figures $5 \mathrm{~b}-\mathrm{d}$ also show that the normalized amplitude of antinodes of $B_{\text {vert }}$ and both E components decrease toward the Earth, which is seen at the fundamental frequency, as well as at the higher harmonics. On the other hand, $B_{\text {hor }}$ (Fig. 5a) always has a maximum around the altitude of the F-region peak. This is in agreement with our earlier results when studying wave characteristics at the fundamental frequency (Prikner et al., 2000). This indicates that the greatest wave amplification takes place around F-region heights. It is important to note that only the $B_{\text {hor }}$ component has a significant value on the ground, reflecting the common view that ground-based signatures of $\mathrm{Pc} 1$ events are due to this component. The remarkable decrease of $B_{\text {vert }}$ and the two $\mathbf{E}$ field components towards the ground is a consequence of increasing electric conductivity towards the lower ionosphere, in particular of the highly conducting E-F1 layer.

\section{Conclusions}

The ionospheric Alfvén resonator (IAR) is known to affect ground-based Pc1 pulsation activity, favoring transmission of waves whose frequency coincides with the first maximum of the transmission coefficient, i.e. to the resonator's fundamental frequency. In this paper we have studied the resonator properties when magnetometer stations in northern Finland registered three simultaneous bands of Pc1 pearls. We found that the frequencies of the observed pearl bands $\left(f_{2} \sim 0.8 \mathrm{~Hz}\right.$, $f_{3} \sim 1.2 \mathrm{~Hz}$ and at $f_{4} \sim 1.45 \mathrm{~Hz}$ ) coincided very well with the third, fourth and fifth maximum of the transmission coefficient spectrum, i.e. with the respective higher harmonic frequencies of the resonator. Furthermore, we found that the wave intensity within each band decreased when the wave frequency deviated from the respective harmonic frequency of the resonator. This gives further evidence for the possibility that the resonator favors wave transmission at selected frequencies (frequency windows), and suggests that it can affect incident Pc1 waves over a notably large frequency range. Since the pearl frequencies were found to correspond to the maxima of the transmission coefficient and minima of the reflection coefficient, the present results do not support the traditional bouncing wave packet model, which assumes that pearls grow at frequencies where the ionospheric reflection has a maximum.

Acknowledgements. J. K., R. K. and K. M. gratefully acknowledge the financial support by the Academy of Finland. F. Z. F. acknowledges the financial support by the Commission of the European Union (research grant INTAS99-0335) and the Russian Fund for Basic Research (research grants 02-05-64610 and 02-05-64612). K. P. thanks T. Bösinger, J. Manninen and J. Kultima for magnetic data, and R. Kuula for EISCAT data. K. P. acknowledges also the financial support of the EU's 5th Frame Programme under the IHP Programme (contract HPRI200100132). The EISCAT Scientific Association is supported by the Suomen Akatemia of Finland, Centre National de la Recherche Scientifique, France, MaxPlanck Gesellschaft, Federal Republic of Germany, National Institute of Polar Research of Japan, Norges Almenvitenskapelige Forskningsrad of Norway, Naturvetenskapliga Forskningsradet of Sweden, and the Science and Engineering Research Council of the United Kingdom.

Topical Editor M. Lester thanks M. Engebretson and D. Wright for their help in evaluating this paper.

\section{References}

Belyaev, P. P., Polyakov, S. V., Rapoport, V. O., and V. Y. Trakhtengertz: The fine structure of the radiation of an Alfvén maser, Geomagn. Aeron., 24, 202-205, 1984.

Belyaev, P. P., Polyakov, S. V., Rapoport, V. O., and Trakhtengertz, V. Y.: The formation of the dynamic spectra of geomagnetic pulsations in the Pc1 range, Geomagn. Aeron., 27, 561-564, 1987.

Benioff, H.: Observations of geomagnetic fluctuations in the period range 0.3 to 120 seconds, J. Geophys. Res, 65, 1413-1422, 1960.

Carpenter, D. L. and Anderson, R. R.: An ISEE/Whistler model of equatorial density in the magnetosphere, J. Geophys. Res., 97, 1097-1108, 1992

Cummings, W. D., O’Sullivan, R. J., and Coleman, Jr., P. J.: Standing Alfvén waves in the ionosphere, J. Geophys. Res., 74, 778793, 1969.

Erlandson, R. E., Anderson, B. J., and Zanetti, L. J.: Viking magnetic and electric field observations of periodic Pc1 waves: Pearl pulsations, J. Geophys. Res., 97, 14 823-14 832, 1992.

Feygin, F. Z., Nekrasov, A. K., Mursula, K., Kangas, J. and Pikkarainen, T.: Coherent multiple Pc1 pulsation bands: Possible evidence for the ionospheric Alfvén resonator, Ann. Geophys., 12, 147-151, 1994.

Fraser, B. J., Kemp, W. J., and Webster, D. J.: Ground-satellite study of a Pc1 ion cyclotron wave event, J. Geophys. Res., 94, 11 855-11 863, 1989.

Greifinger, C. and Greifinger, P.: Theory of Hydromagnetic propagation in the ionospheriv waveguide, J. Geophys. Res., 73, 74737490, 1968.

Jacobs, J. A. and Watanabe, T.: Micropulsation whistlers, J. Atmos. Terr. Phys., 26, 825-829, 1964.

Kenney, J. F. and Knaflich, H. B.: A systematic study of structured micropulsations, J. Geophys. Res., 72, 2857-2869, 1967.

Kerttula, R., Mursula, K., Pikkarainen, T., and Kangas, J.: Stormtime Pc1 activity at high and middle latitudes, J. Geophys. Res., 106, 6213-6227, 2001.

Kozyra, J. U., Cravens, T. E., Nagy, A. F., Fontheim, E. G., and Ong, R. S. B.: Effects of energetic heavy ions on electromag- 
netic ion cyclotron wave generation in the plasmapause region, J. Geophys. Res., 89, 2217-2233, 1984.

Lysak, R. L.: Feedback instability of the ionospheric resonant cavity, J. Geophys. Res., 96, 1553-1568, 1991.

Lysak, R. L.: Generalized model of the ionospheric Alfvén resonator, in: Auroral Plasma Dynamics, AGU, Geophysical Monograph, 80, 121-128, 1993.

Lysak, R. L.: Propagation of Alfvén waves through the ionosphere: dependence on ionospheric parameters, J. Geophys. Res., 104, (A5), 10 017-10 030, 1999.

Mauk, B. H., McIlwain, C. E., and McPherron, R. L.: Helium cyclotron resonance within the Earth's magnetosphere, Geophys. Res. Lett., 8, 103, 1981.

Mursula, K., Rasinkangas, R., Bösinger, T., Erlandson, R. E., and P.-A. Lindqvist: Nonbouncing Pc1 wave bursts, J. Geophys. Res., 102, 17 611-17 624, 1997.

Mursula, K., Prikner, K., Feygin, F. Z., Bräysy, T., Kangas, J., Kerttula, R., Pollari, P., Pikkarainen, T., and Pokhotelov, O. A.: Nonstationary Alfvén resonator: new results on Pc1 pearls and IPDP events, J. Atmos. Sol.-Terr. Phys., 62, 299-309, 2000.

Mursula, K., Bräysy, T., Niskala, K., Mozer, F., and Russell, C. T.: Pc1 pearls revisited: Structured electromagnetic ion cyclotron waves on Polar satellite and on ground, J. Geophys. Res., 106, 29543-29 553, 2001.

Obayashi, T.: Hydromagnetic whistlers, J. Geophys. Res., 70, 1069-1078,1965.

Plyasova-Bakounina, T. A., Kangas, J., Mursula, K., Molchanov, O. A., and Green, A. W.: Pc 1-2 and Pc 4-5 pulsations observed at a network of high-latitude stations, J. Geophys. Res., 101, 10965 $10973,1996$.

Polyakov, S. V. and Rapoport, V. O.: Ionospheric Alfvén resonator, Geomagn. Aeron., 21, 610-614, 1981.

Prikner, K., Mursula, K., Feygin, F. Z., Kangas, J., Kerttula, R., Pikkarainen, T., Pokhotelov, O. A., and Vagner, V.: Nonstationary Alfvén resonator: vertical profiles of wave characteristics, J. Atmos. Sol.-Terr. Phys., 62, 311-322, 2000.
Prikner, K., Mursula, K., Kangas, J., and Feygin, F. Z.: Ionospheric Alfvén resonator control over the frequency-variable Pc1 event in Finland on May 14, 1997, Studia Geoph. et Geod., 45, 363 381, 2001.

Prikner, K., Mursula, K., Kangas, J., Feygin, F. Z., and Kerttula, R.: Numerical simulation of the high-latitude non-stationary ionospheric Alfvén resonator during an IPDP event, Studia Geoph. et Geod., 46, 507-526, 2002.

Prikner, K. and Vagner, V.: Numerical modelling of the ionospheric filtration of ULF micropulsation signal, Studia Geoph. et Geod., 27, 173-190, 1983.

Prikner, K. and Vagner, V.: Numerical solution to the problem of ionospheric filtration of ULF waves in the Pc1 range. The total wave field inside the ionospheric transition layer, Studia Geoph. et Geod., 35, 90-99, 1991.

Rasinkangas, R., Mursula, K., Kremser, G., Singer, H. J., Fraser, B. J., Korth, A., and Hughes, W. J.: Simultaneous occurrence of Pc5 and Pc1 pulsations in the dawnside magnetosphere: CRRES observations, in: Solar-wind Sources of Magnetospheric UltraLow-Frequency Waves, Geophysical Monograph, 81, 417-424, edited by Engebretson, M. J., Takahashi, K., and Scholer, M., AGU, 1994.

Rasinkangas, R. and Mursula, K.: Modulation of magnetospheric EMIC waves by Pc 3 pulsations of upstream origin, Geophys. Res. Lett., 25, 869-872, 1998.

Takahashi, K. and McPherron, R. L.: Harmonic structure of Pc3-4 pulsations, J. Geophys. Res., 87 (A3), 1504-1516, 1982.

Vagner, V.: Numerical solution of ionospheric filtration of ULF waves (Part 1 - Method), Travaux Géophysiques, XXX (No 575), 199-229, 1982.

Young, D. T., Perraut, S., Roux, A., de Villedary, C., Gendrin, R., Korth, A., Kremser, G., and Jones, D.: Wave-particle interactions near $\Omega_{\mathrm{He}}^{+}$observed on GEOS 1 and 21 . Propagation of ion cyclotron waves in $\mathrm{He}^{+}$-rich plasma, J. Geophys. Res., 86, 6755-6772, 1981. 